\title{
Characterisation of Electroless Deposited Cobalt by Hard and Soft X-ray Photoemission Spectroscopy
}

\author{
A. Brady-Boyd ${ }^{1}$, R. O’Connor ${ }^{1}$, S. Armini ${ }^{2}$, V. Selvaraju ${ }^{1}$, G. Hughes ${ }^{1}$ and J.Bogan ${ }^{1}$ \\ ${ }^{1}$ School of Physical Sciences, Dublin City University, Glasnevin, Dublin 9, Ireland email: anita.brady32@mail.dcu.ie \\ ${ }^{2}$ IMEC, Kapeldreef 75, B-3001 Heverlee, Leuven, Belgium
}

\begin{abstract}
Electroless deposited (ELD) cobalt with palladium as a catalyst, and an underlying self-assembled monolayer (SAM) was investigated for potential use in advanced complementary metal oxide semiconductor (CMOS) applications using both hard (HAXPES) and soft (XPS) x-ray photoelectron spectroscopy. HAXPES spectra established the uniformity of the deposited Co film and the nature of the buried $\mathrm{Co}-\mathrm{Si}$ interface $\sim 20 \mathrm{~nm}$ below the surface. The Pd is seen to diffuse through the Co following thermal annealing. While the deposited Co film is predominantly metallic, Co-silicide forms at the Co-Si interface upon deposition and decomposes with thermal anneal up to $500^{\circ} \mathrm{C}$.
\end{abstract}

\section{INTRODUCTION}

With the continued aggressive scaling toward smaller feature sizes, the need has arisen for alternative materials to copper to act as the interconnect metal. Various materials such as metal silicides [1, 2], graphene [3] and Co [4, 5] are currently being investigated to replace $\mathrm{Cu}$. With such small dimensions it can be difficult for deposition techniques such as chemical and physical vapour deposition (CVD, PVD) to achieve seamless fill of high aspect ratio trenches. Traditional bottom-up electrodeposition methods require a conductive seed layer whose continuity is a challenge in high aspect ratio and small pitch structures. An electroless deposition (ELD) approach can provide viable solutions for these problems. An ELD process is attractive due to the fact it can be used to deposit on metals and insulators upon catalyst placement, it can achieve very uniform thin films, and it is a relatively lowcost process. ELD cobalt is a strong candidate to fully replace copper as the via prefill or interconnect Jiang et al [4] and Van der Veen et al [5] have shown that using cobalt as the via metal, it can outperform copper with feature sizes below 28 $\mathrm{nm}$ and $15 \mathrm{~nm}$ respectively, in terms of resistance and electromigration resistance. In this method there is no barrier required for dense low-k dielectrics, so the cobalt is free to take up the full area of the via. In the newest technology node In the newest technology node $\mathrm{Co}$ has replaced $\mathrm{Cu}$ in the first three metal lines [6]. SAMs have also been demonstrated as a valuable adhesion promoter, potential pore sealant for low- $\mathrm{k}$ dielectrics, and as a blocker for use in selective area atomic layer deposition (ALD) [7, 8].

\section{EXPERIMENTAL DETAILS AND METHOD}

Native silicon dioxide on $\mathrm{Si}$ (100) substrates were cleaned by 15-minute exposure to UV-ozone treatment in a Jelight UVO Cleaner. Subsequently, SAMs derived from (3trimethoxysilylpropyl) diethylenetriamine (DETA) precursor were deposited via vapour phase deposition on the UVO cleaned substrates. SAM films were deposited using $100 \mu \mathrm{L}$ of the precursor at a temperature of $140^{\circ} \mathrm{C}$ for $1 \mathrm{hr}$ with a chamber pressure of $\approx 10$ mbar. The substrates were then immersed in a $\mathrm{PdCl}_{2}$ acidic solution, with a $\mathrm{pH}$ of 2 , for 2 minutes and then rinsed for 2 minutes with deionized (DI) water. Co was deposited by ELD to a thickness of $20 \mathrm{~nm}$ from a solution of $\mathrm{CoSO}_{4}, \mathrm{NH}_{4} \mathrm{Cl}$ and water with a dimethyl ammonium borane (DMAB) reducing agent. Following Co deposition, the samples were annealed in a forming gas atmosphere at $420^{\circ} \mathrm{C}$ for 15 minutes.

HAXPES and XPS measurements were performed at Diamond Light Source, UK. Due to the high photon energy employed by HAXPES, buried interfaces up to $\sim 20 \mathrm{~nm}$ deep are accessible compared to $\sim 8 \mathrm{~nm}$ in conventional XPS. In this facility one can illuminate a precise location on the sample under consideration using both soft and hard x-rays simultaneously. This gives the unique advantage of concurrently recording surface and bulk properties during each experimental step. The soft $\mathrm{x}$-ray incident photon energy was $1.2 \mathrm{keV}$, while the hard $\mathrm{x}$-ray incident photon energy was $5.9 \mathrm{keV}$. A VG Scienta EW4000 HAXPES energy analyser was used to record the spectra. The sample was placed in the ultra-high vacuum chamber at a base pressure of $\sim 5 \times 10^{-10}$ mbar. The sample received three anneals; $300^{\circ} \mathrm{C}, 400^{\circ} \mathrm{C}$ and $500^{\circ} \mathrm{C}$ in-vacuo and photoemission spectra were acquired after each anneal. All spectra are shifted to the $\mathrm{C} 1 \mathrm{~s}$ at a binding energy position of $284.8 \mathrm{eV}$.

\section{Results AND Discussion}

\section{A. Characterisation of ELD Co Films}

In this study DETA is employed as an adhesion promoter for the Pd. The Pd adheres to the amino terminal group of the DETA and forms a seed layer ( 1nm) for the ELD Co. Survey spectra taken in the hard x-ray (Fig. 1(a)) regime are dominated by the ELD Co signal while the soft x-ray (Fig. 1(b)) regime is dominated by the oxygen signal from surface oxide. One important point to note is that the $\mathrm{Si} 1 \mathrm{~s}$, at a binding energy of $\sim 1839 \mathrm{eV}$, is visible in the HAXPES scans. 
This indicates that the entirety of the Co film $(\sim 20 \mathrm{~nm})$ is accessible as the only source of $\mathrm{Si}$ is the underlying substrate. From the ELD deposition, nitrogen, carbon, and boron have been incorporated into the film with the carbon and nitrogen concentrations decreasing with thermal annealing. This is observed in both hard and soft regimes. The Pd does not become evident until after the $400^{\circ} \mathrm{C}$ anneal. The nitrogen and palladium are not easily observed in the survey spectra but are accessible in narrow energy window scans. The soft X-ray spectra show a large increase in intensity in both the B 1s and $\mathrm{O} 1 \mathrm{~s}$ following thermal annealing.

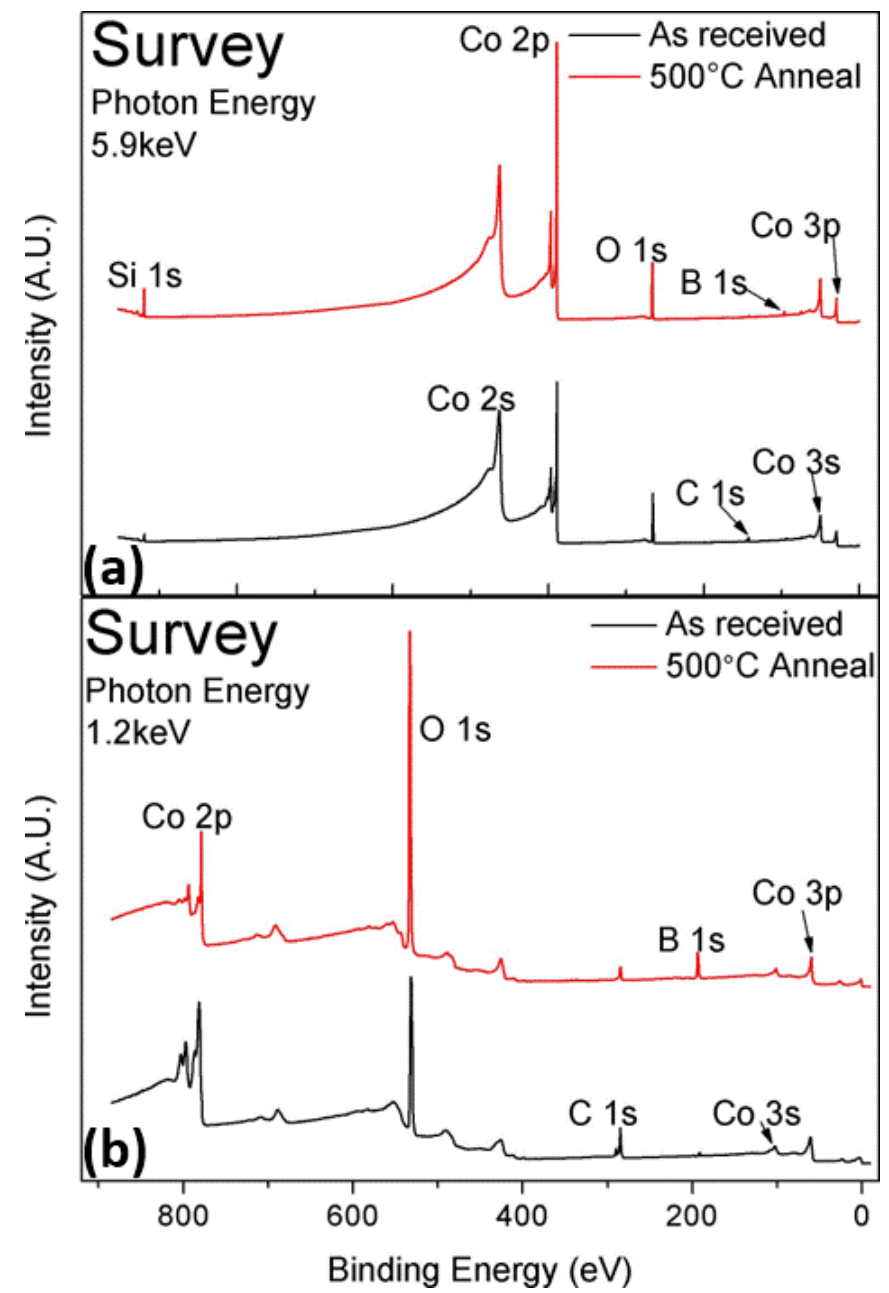

Fig. 1(a) Hard and (b) soft X-ray survey scans showing the first and last experiment steps. All peaks are labelled except for the N 1s and Pd 3d which are not easily seen in the survey spectra.

Fig. 2 shows the $\operatorname{Pd} 2 p$ which a literature review suggests, is the first-time this peak has been investigated with HAXPES. The $\mathrm{Pd}$ does not become evident until after the $400^{\circ} \mathrm{C}$ anneal has been performed. One possible reason for this is that the $\mathrm{Pd}$ is diffusing through the Co film. The peak appears to be in a metallic state with the $2 \mathrm{p}_{3 / 2}$ at binding energy of $3174.3 \mathrm{eV}$ and the $2 \mathrm{p}_{1 / 2}$ at a binding energy of $3331.3 \mathrm{eV}$ and a possible oxide shoulder on the higher binding energy side of both peaks. This was determined by analysis of the Pd $3 d$ (not shown) which has a binding energy of $335.4 \mathrm{eV}$ and is therefore in the correct position for Pd metal.
Fig. 3 shows the Co $2 \mathrm{p}$ spectrum recorded with both hard and soft X-rays. From the HAXPES spectrum in Fig.3(a) the as-received sample shows a small surface oxide, which is present on the higher binding energy (HBE) side of the metallic component peak. This peak intensity is decreased by the sequence of anneals and by the $500^{\circ} \mathrm{C}$ anneal the oxide is

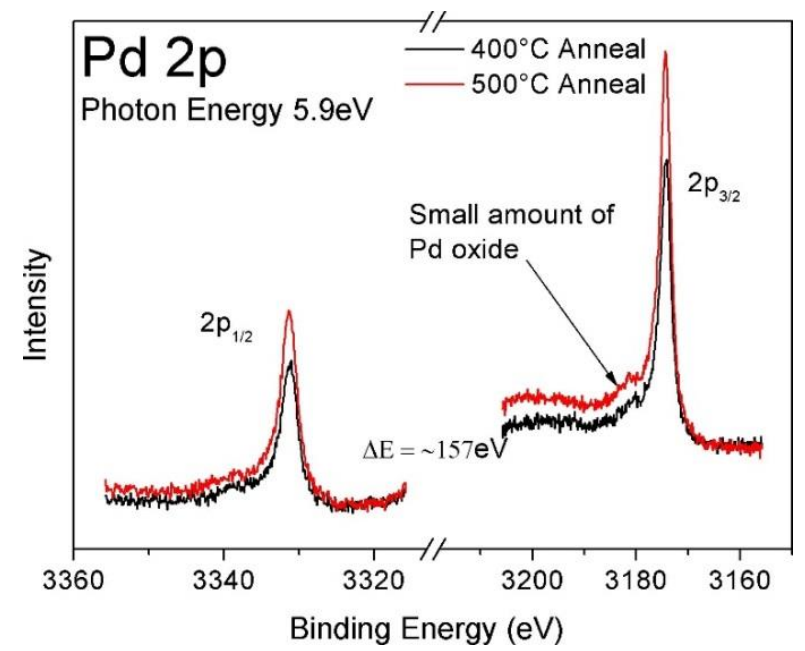

Fig. 2

The Pd $2 p$ spectrum showing a metallic profile with a slight oxide on the HBE side of the peak.

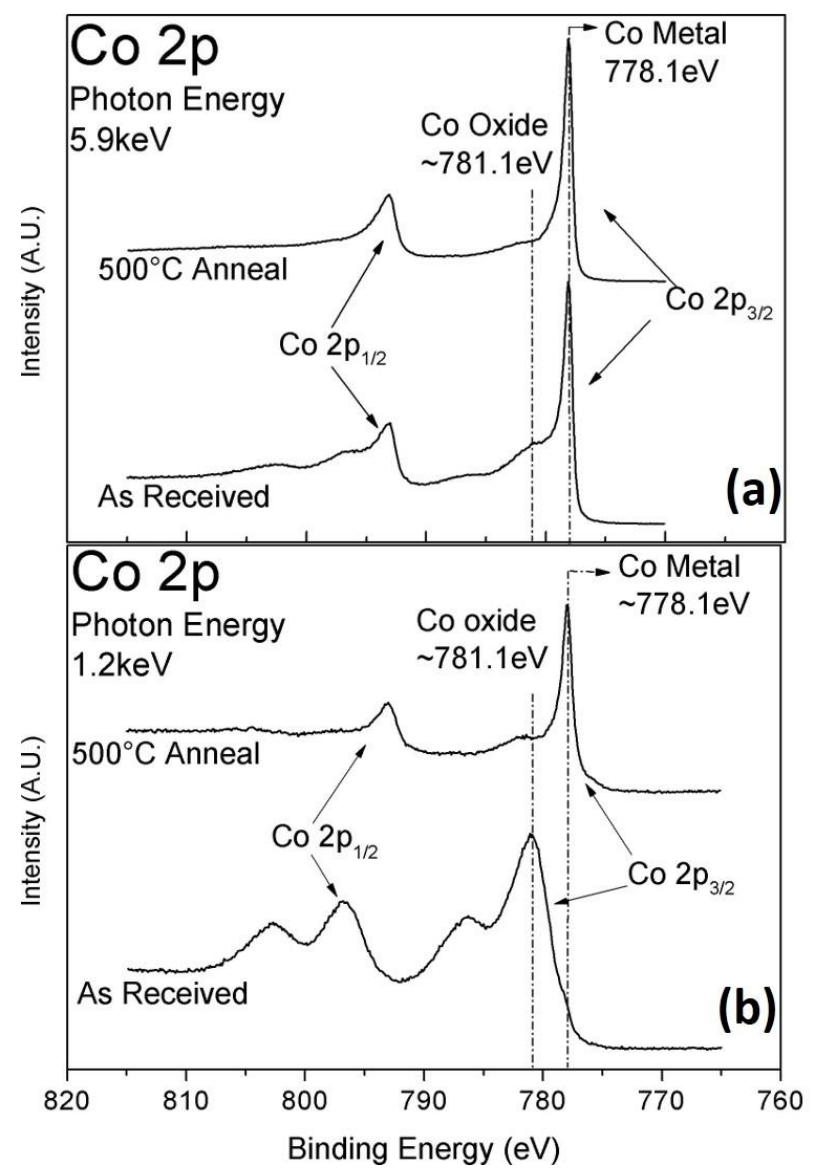

Fig. 3 The Co $2 p$ in the (a) hard X-rays shows a mostly metallic peak with some oxide in the HBE side. The (b) soft X-ray scans reveal that this oxide is surface localized. Both spectra show how this oxide is removed with thermal anneal. 
almost completely removed. The XPS spectra in Fig.3(b) confirm that the oxide is surface localized. The data suggests that the top $\sim 5 \mathrm{~nm}$ is primarily Co-oxide. There is however, a small metallic shoulder on the lower binding energy (LBE) side of the oxide peak. This can be seen to grow with each thermal anneal while the oxide component decreases until finally after the $500{ }^{\circ} \mathrm{C}$ anneal the surface oxide has been almost removed. These spectra demonstrate that the ELD process has deposited a high quality metallic film in which the residual surface oxide is easily reduced by thermal annealing.

To ascertain if there was any evidence of the DETA SAM, the high energy spectra of the $\mathrm{C} 1 \mathrm{~s}$ and $\mathrm{N} 1 \mathrm{~s}$ (Fig. 4) were examined. The $\mathrm{N}$ 1s has just one broad peak with two component peaks. These peaks have been attributed to $\mathrm{C}-\mathrm{N}-\mathrm{O}$ bonds at $399.35 \mathrm{eV}$ and the other is attributed to boron nitride (BN) at $398.1 \mathrm{eV}$. The reducing agent used during the ELD process is the source of boron. The signal to noise ratio is poorer for the nitrogen than the other spectra due to small quantity of nitrogen in the film. With subsequent anneals this signal to noise ratio deteriorates, as these nitrogen species decompose and the corresponding peak intensity decreases. In soft X-rays spectra (not shown) there is a $\mathrm{N} 1 \mathrm{~s}$ peak present. If the only source of $\mathrm{N}$ is the DETA SAM, then there should be no visible $\mathrm{N}$ 1s peak in these spectra as the soft X-rays are surface sensitive $(\sim 8 \mathrm{~nm})$. This would imply that $\mathrm{N}$ has been incorporated into film. However, this makes identifying the DETA SAM extremely difficult.

Looking at the $\mathrm{C} 1 \mathrm{~s}$ initially there are two main peaks with several component peaks, visible in the spectra. A peak at LBE which is attributed to C-C bonds at $284.8 \mathrm{eV}, \mathrm{C}-\mathrm{O} / \mathrm{C}-\mathrm{N}-$ $\mathrm{O}$ bonds at $\sim 286 \mathrm{eV}, \mathrm{C}=\mathrm{O}$ bonds at $\sim 288.4 \mathrm{eV}$ and a peak at $\mathrm{HBE}$ which has been attributed to cobalt carbonate at $289.8 \mathrm{eV}$. Following the $300^{\circ} \mathrm{C}$ anneal the carbonate peak intensity is greatly reduced and by the $500^{\circ} \mathrm{C}$ anneal it has been fully decomposed. The $\mathrm{C}=\mathrm{O}$ component peak is also removed by the thermal anneals. The main component peak remains quite strong throughout the experiment and suggests that the $\mathrm{C}$ has become incorporated into the film during the ELD process. This again makes identifying the $\mathrm{C}$ signal from the DETA SAM very difficult.

Fig. 5 displays the deconvoluted hard $\mathrm{X}$-ray $\mathrm{O} 1 \mathrm{~s}$ and $\mathrm{B} 1 \mathrm{~s}$ spectra. The as-received spectra show the $\mathrm{B}$ has formed Coboride and $\mathrm{BN}$ while the $\mathrm{Co}$ oxide and carbonate dominated the $\mathrm{O} 1 \mathrm{~s}$. Also, present in the $\mathrm{O} 1 \mathrm{~s}$ is a small boron oxide peak which grows upon anneal. This can also be seen in the B 1s following the $300^{\circ} \mathrm{C}$ anneal. The oxygen released from the decomposition of the Co oxide and carbonate is not desorbed from the surface but instead forms a bond with the B to form a boron oxide. As the B oxidizes further both spectra can be seen to shift to a higher binding energy. By the $500^{\circ} \mathrm{C}$ anneal the boron has become fully oxidised by forming $\mathrm{B}_{2} \mathrm{O}_{3}$. The corresponding component peaks in both the $\mathrm{B} 1 \mathrm{~s}(193.3 \mathrm{eV})$ and $\mathrm{O} 1 \mathrm{~s}(532.9 \mathrm{eV})$ are now in the correct binding energy position for $\mathrm{B}_{2} \mathrm{O}_{3}[9,10]$.

\section{B. The Si-Co Interface}

In order to understand the interactions between the Co overlayer and the silicon substrate, the Si 1s peak was studied in detail and the deconvoluted spectra is presented in Fig. 6. Initial data from the as-received sample reveals the $\mathrm{Si}$ to

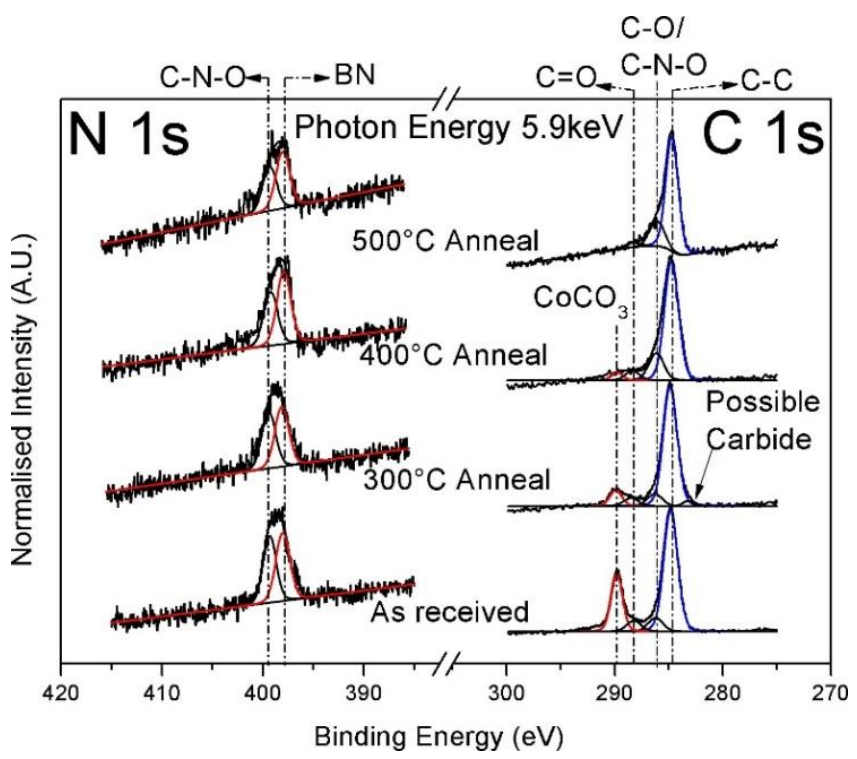

Fig.4 The normalised $\mathrm{N} 1 \mathrm{~s}$ and $\mathrm{C} 1 \mathrm{~s}$, show a deterioration in the signal to noise for the $\mathrm{N}$ 1s and the decomposition of the $\mathrm{C}$ 1s with increasing anneal temperature

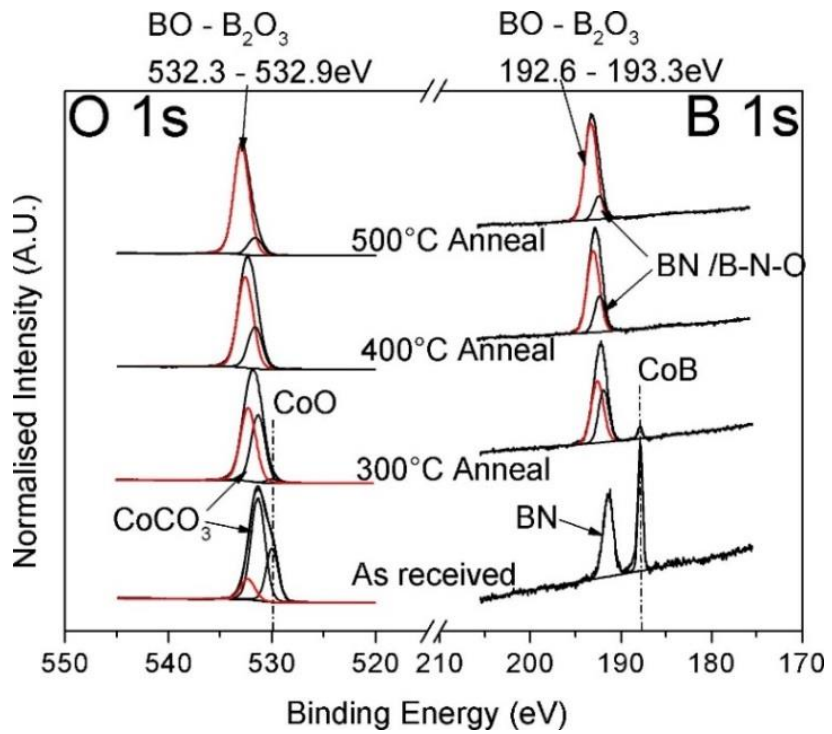

Fig. 5 The deconvoluted $\mathrm{O} 1 \mathrm{~s}$ and $\mathrm{B} 1 \mathrm{~s}$ hard $\mathrm{X}$-ray spectra showing the reduction of the $\mathrm{CoO}$ and $\mathrm{CoCO}_{3}$ and the oxidation of the $\mathrm{B} 1 \mathrm{~s}$.

comprise of several different components which have been assigned to the bulk $\mathrm{Si}$ at $1839.1 \mathrm{eV}$, two Co silicide phases, one at $1839.5 \mathrm{eV}$ and the other at $1838.7 \mathrm{eV}, \mathrm{SiO}_{2}$ at $1843.7 \mathrm{eV}$ and sub oxide states on the HBE side of the bulk peak. The silicide phase on the HBE side has been attributed to CoSi [9, 10] while the silicide on the LBE side has been attributed to $\mathrm{Co}_{2} \mathrm{Si}[11,12]$. There is also a "pre-peak" observed on the LBE side. This "pre-peak" has previously been observed in a $\mathrm{Si} 1 \mathrm{~s}$ iron silicide spectra [15]. Following the $300^{\circ} \mathrm{C}$ anneal 
the $\mathrm{Co}_{2} \mathrm{Si}$ phase grows significantly while the bulk $\mathrm{Si}$ component peak reduces as it is consumed to form more silicide. The $400^{\circ} \mathrm{C}$ anneal sees the breakdown of this phase as the bulk Si signal increases.

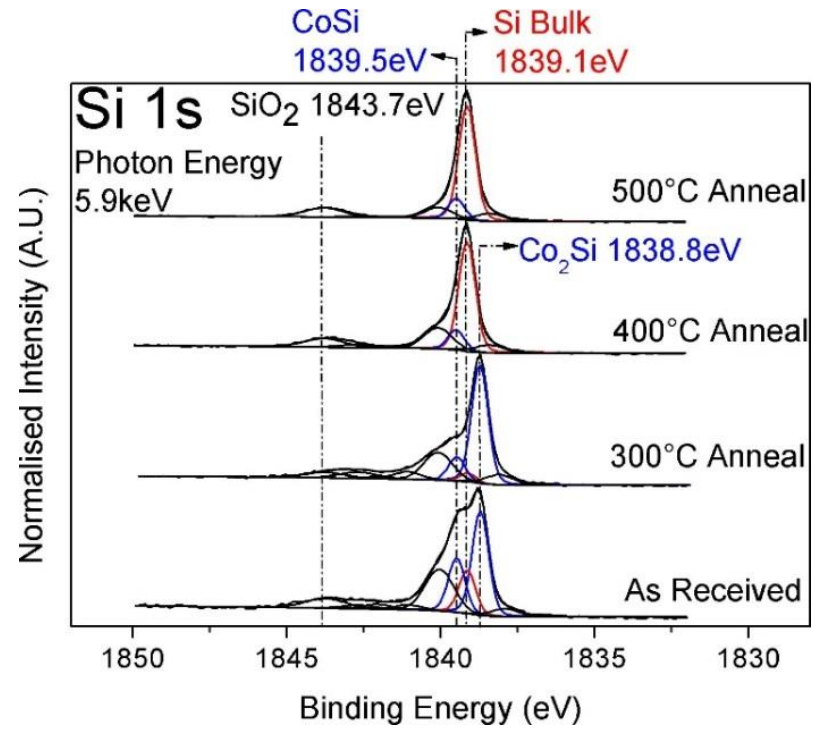

Fig.5 Peak fitted Si 1s Spectra showing two silicide phases which with thermal anneal decompose.

The $\mathrm{Si}^{2+}$ and the $\mathrm{Si}^{3+}$ sub oxides have almost completely decomposed and released enough oxygen to breakdown this Co rich phase. The CoSi phase being more stable, remains. By the $500^{\circ} \mathrm{C}$ the bulk $\mathrm{Si}, \mathrm{CoSi}$ and $\mathrm{SiO}_{2}$ peaks have become stable and have not changed appreciably since the last anneal. The $\mathrm{Si}^{1+}$ is still quite large but it is expected with a higher annealing temperature that this oxide phase would decompose.

\section{Conclusion}

From this study it can be concluded that SAMs have been successful in trapping the Pd which in turn was successful in promoting the reaction for the electroless deposition. High energy spectra show that the Co film is a superior quality metallic film with a small amount of surface oxide present which can be eliminated by thermal annealing. The quality of the film is of the upmost importance for devices as any oxide can decrease the conductivity. It is clear that boron has become incorporated into the film and bonds with the released oxygen to form $\mathrm{B}_{2} \mathrm{O}_{3}$. The carbon and nitrogen introduced from the deposition, reduce with each thermal anneal. It cannot be confirmed if the DETA SAM has survived the ELD process or if it has been etched away. It has been shown that the ELD process forms two cobalt silicide phases at the Si-Co interface which are unstable at high temperatures.

\section{ACKNOWLEDGMENT}

The authors would like to gratefully acknowledge financial support from the SFI PI Programme under Grant No. 13/1A/1955. The authors also gratefully acknowledge Diamond Light Source for time on beamline i09 under proposal SI19698-1. The research leading to this result has been supported by the project CALIPSOplus under the Grant Agreement 730872 from the EU Framework Programme for Research and Innovation HORIZON 2020.This work was carried out within the IMEC Industrial Affiliation Programme on Advanced Interconnects (IIAP).

\section{REFERENCES}

[1] Z. W. Zhu, X. D. Gao, Z. Bin Zhang, Y. H. Piao, C. Hu, D. W. Zhang, and D. P. Wu, "Formations and morphological stabilities of ultrathin $\mathrm{CoSi} 2$ films," Chinese Phys. B, vol. 21, no. 8, 2012.

[2] M. Bhaskaran, S. Sriram, T. S. Perova, V. Ermakov, G. J. Thorogood, K. T. Short, and A. S. Holland, "In situ micro-Raman analysis and X-ray diffraction of nickel silicide thin films on silicon," Micron, vol. 40, no. 1, pp. 89-93, 2009.

[3] I. Asselberghs, M. Politou, B. Soree, S. Sayan, D. Lin, P. Pashaei, C. Huyghebaert, P. Raghavan, I. Radu, and Z. Tokei, "Graphene wires as alternative interconnects," in 2015 IEEE International Interconnect Technology Conference and 2015 IEEE Materials for Advanced Metallization Conference (IITC/MAM), 2015, pp. 317-320.

[4] Yu Jiang, P. Nalla, Y. Matsushita, G. Harm, Jingyan Wang, A. Kolics, L. Zhao, T. Mountsier, P. Besser, and Hui-Jung Wu, "Development of electroless Co via-prefill to enable advanced BEOL metallization and via resistance reduction," in 2016 IEEE International Interconnect Technology Conference / Advanced Metallization Conference (IITC/AMC), 2016, pp. 111-113.

[5] M. H. Van Der Veen, K. Vandersmissen, D. Dictus, S. Demuynck, R. Liu, X. Bin, P. Nalla, A. Lesniewska, L. Hall, K. Croes, L. Zhao, J. Bömmels, A. Kolics, and Z. Tökei, "Cobalt bottom-up contact and via prefill enabling advanced logic and DRAM technologies," in 2015 IEEE International Interconnect Technology Conference and 2015 IEEE Materials for Advanced Metallization Conference, IITC/MAM 2015, 2015, no. v, pp. $25-27$.

[6] C. Auth, A. Aliyarukunju, M. Asoro, D. Bergstrom, V. Bhagwat, J. Birdsall, N. Bisnik, M. Buehler, V. Chikarmane, G. Ding, Q. Fu, H. Gomez, W. Han, D. Hanken, M. Haran, M. Hattendorf, R. Heussner, H. Hiramatsu, B. Ho, S. Jaloviar, I. Jin, S. Joshi, S. Kirby, S. Kosaraju, H. Kothari, G. Leatherman, K. Lee, J. Leib, A. Madhavan, K. Marla, H. Meyer, T. Mule, C. Parker, S. Parthasarathy, C. Pelto, L. Pipes, I. Post, M. Prince, A. Rahman, S. Rajamani, A. Saha, J. D. Santos, M. Sharma, V. Sharma, J. Shin, P. Sinha, P. Smith, M. Sprinkle, A. St. Amour, C. Staus, R. Suri, D. Towner, A. Tripathi, A. Tura, C. Ward, and A. Yeoh, "A 10nm high performance and low-power CMOS technology featuring 3 rd generation FinFET transistors, Self-Aligned Quad Patterning, contact over active gate and cobalt local interconnects," 2017 IEEE Int. Electron Devices Meet., p. 29.1.1-29.1.4, 2017.

[7] A. Brady-Boyd, R. O'Connor, S. Armini, V. Selvaraju, G. Hughes, and J. Bogan, "On the use of (3-trimethoxysilylpropyl)diethylenetriamine selfassembled monolayers as seed layers for the growth of Mn based copper diffusion barrier layers," Appl. Surf. Sci., vol. 427, pp. 260-266, 2018.

[8] F. S. Minaye Hashemi, B. R. Birchansky, and S. F. Bent, "Selective Deposition of Dielectrics: Limits and Advantages of Alkanethiol Blocking Agents on Metal-Dielectric Patterns," ACS Appl. Mater. Interfaces, vol. 8, no. 48, pp. 33264-33272, 2016.

[9] B. J. Matsoso, K. Ranganathan, B. K. Mutuma, T. Lerotholi, G. Jones, and N. J. Coville, "Synthesis and characterization of boron carbon oxynitride films with tunable composition using methane, boric acid and ammonia," New J. Chem., vol. 41, no. 17, pp. 9497-9504, 2017.

[10] Z. Pan, Y. Yang, J. Huang, B. Ren, H. Yu, R. Xu, H. Ji, L. Wang, and L. Wang, "Study on the preparation of boron-rich film by magnetron sputtering in oxygen atmosphere," Appl. Surf. Sci., vol. 388, pp. 392-395, 2016.

[11] J. S. Pan, R. S. Liu, Z. Zhang, S. W. Poon, W. J. Ong, and E. S. Tok, "Co growth on $\operatorname{Si}\left(\begin{array}{lll}0 & 0 & 1\end{array}\right)$ and $\operatorname{Si}\left(\begin{array}{lll}1 & 1 & 1\end{array}\right)$ surfaces: Interfacial interaction and growth dynamics," Surf. Sci., vol. 600, no. 6, pp. 1308-1318, 2006.

[12] I. Y. Hwang, J. H. Kim, S. K. Oh, H. J. Kang, and Y. S. Lee, "Ultrathin cobalt silicide film formation on $\mathrm{Si}(100)$," Surf. Interface Anal., vol. 35, no. 2, pp. 184-187, 2003.

[13] M. V. Gomoyunova, G. S. Grebenyuk, and I. I. Pronin, "Binding energies of $\mathrm{Si} 2 \mathrm{p}$ and Co $3 \mathrm{p}$ electrons in cobalt silicides," Tech. Phys. Lett., vol. 37, no. 12, pp. 1124-1126, 2011.

[14] C. Van Bockstael, K. De Keyser, J. Demeulemeester, A. Vantomme, R. L. Van Meirhaeghe, C. Detavernier, J. L. Jordan-Sweet, and C. Lavoie, "In situ study of the formation of silicide phases in amorphous Co-Si mixed layers," Microelectron. Eng., vol. 87, no. 3, pp. 282-285, 2010.

[15]L. Badía-Romano, J. Rubín, F. Bartolomé, C. Magén, J. Bartolomé, S. N. Varnakov, S. G. Ovchinnikov, J. Rubio-Zuazo, and G. R. Castro, "Morphology of the asymmetric iron-silicon interfaces," J. Alloys Compd., vol. 627, pp. 136-145, 2015. 
